\title{
Visualization of the homogeneous charge compression ignition/controlled autoignition combustion process using two-dimensional planar laser-induced fluorescence imaging of formaldehyde
}

\author{
Z Peng*, H Zhao and N Ladommatos \\ Department of Mechanical Engineering, Brunel University, Uxbridge, Middlesex, UK
}

\begin{abstract}
The paper reports an investigation into the homogeneous charge compression ignition/ controlled autoignition ( $\mathrm{HCCI} / \mathrm{CAI})$ combustion process using the two-dimensional planar laserinduced fluorescence (PLIF) technique. The PLIF of formaldehyde formed during the low-temperature reactions of $\mathrm{HCCI} / \mathrm{CAI}$ combustion was excited by a tunable dye laser at $355 \mathrm{~nm}$ wavelength and detected by a gated intensified charge-coupled device (ICCD) camera. Times and locations of the two-stage autoignition of $\mathrm{HCCI} / \mathrm{CAI}$ combustion were observed in a single-cylinder optical engine for several fuel blends mixed with n-heptane and iso-octane. The results show, when pure n-heptane was used, that the initial formation of formaldehyde and its subsequent burning were closely related to the start of the low-temperature heat-release stage and the start of the main heat-release stage of HCCI combustion respectively. Meanwhile, it was found that the formation of formaldehyde was more affected by the charge temperature than by the fuel concentration. However, its subsequent burning or the start of main heat-release combustion took place at those areas where both the fuel concentration and the charge temperature were sufficiently high. As a result, it was found that the presence of stratified residual gases affected both the spatial location and the temporal site of autoignition in an $\mathrm{HCCI} / \mathrm{CAI}$ combustion engine. All studied fuels were found having similar formaldehyde formation timings with n-heptane. This means that the presence of iso-octane apparently did not affect the start of low-temperature reactions. However, the heat release during the low-temperature reaction was significantly reduced with the presence of iso-octane in the studied fuels. In addition, the presence of iso-octane retarded the start of the main combustion stage.
\end{abstract}

Keywords: planar laser-induced fluorescence (PLIF) measurement, homogeneous charge compression ignition ( $\mathrm{HCCI}$ ), controlled autoignition (CAI), autoignition, formaldehyde

\section{NOTATION}

ABDC after bottom dead centre

ATDC after top dead centre

BTDC before top dead centre

CAD crank angle degree

CAI controlled autoignition

$\mathrm{CO}$ carbon monoxide

d.c. direct current

EGR exhaust gas recirculation
$\mathrm{HC}$

$\mathrm{HCCI}$

IC

ICCD

LIF

MFB

$\mathrm{NO}_{x}$

NTC

PFI

PLIF

RON

SI

VVA

VVT

$\lambda$ hydrocarbons

homogeneous charge compression ignition internal combustion

intensified charge-coupled device

laser-induced fluorescence

mass fraction burnt

nitrogen oxides

negative temperature coefficient

port fuel injection

planar laser-induced fluorescence

research octane number

spark ignition

variable valve actuation

variable valve timing

for publication on 15 July 2003

* Corresponding author: Department of Mechanical Engineering, Brunel

University, Uxbridge, Middlesex UB8 $3 P H, U K$. 


\section{INTRODUCTION}

Homogeneous charge compression ignition/controlled autoignition ( $\mathrm{HCCI} / \mathrm{CAI})$ engine combustion is currently a topic of intense interest and is being widely researched due to its potential to provide lower emissions and better fuel economy over conventional internal combustion (IC) engines [1-3]. It can be employed at partload conditions under which the lean homogeneous mixture autoignites at multiple locations in the cylinder. Because of the absence of high-temperature regions, little $\mathrm{NO}_{x}$ is formed during combustion. Meanwhile, owing to the homogeneity of the mixture, negligible soot is formed. The lean homogeneous mixture burns at a relatively low temperature, resulting in low heat loss and hence high fuel efficiency. In addition, no throttling is needed for an HCCI/CAI gasoline engine, leading to better efficiency. As the ignition process relies on spontaneous autoignition, there is no direct means of controlling the start and the duration of combustion for this combustion process. However, the ignition timing and the combustion speed can be adjusted by controlling the in-cylinder exhaust gas recirculation (EGR) concentration and the in-cylinder charge temperature. A convenient method for controlling both the in-cylinder EGR concentration and the in-cylinder charge temperature is to adjust the EGR rate or residual exhaust gas rate in the cylinder. Recent developments in variable valve timing (VVT) and variable value actuation (VVA) systems have made those controls available over a wide range of operating conditions and some engines have run an $\mathrm{HCCI} / \mathrm{CAI}$ combustion successfully without external heating or a variable compression ratio [4-5].

$\mathrm{HCCI} / \mathrm{CAI}$ combustion is mainly controlled by the autoignition chemistry of hydrocarbon fuels. Previous studies of autoignition chemistry have been carried out in order to understand the process leading to knocking combustion. These studies have shown that hydrocarbon autoignition is mainly dependent on degenerately branched chain reactions and the reaction delay time is affected by many factors. The fuel's molecular size and structure play significant roles in the autoignition process. Paraffin fuels that contain the straight-chain structure $-\mathrm{CH}_{2}-\mathrm{CH}_{2}-\mathrm{CH}_{2}-$ display a two-stage autoignition process under a modest ignition temperature. The twostage process involves low-temperature reactions followed by hot autoignition combustion (the main combustion stage). Between these two reaction stages, there is a negative temperature coefficient (NTC) period during which there is very little heat released. With the development of autoignition research, some hydrocarbon autoignition models, including reduced chemical kinetic models and detailed kinetic mechanisms, have been developed [6-8].

In order to study the autoignition process involved in $\mathrm{HCCI} / \mathrm{CAI}$ combustion, these autoignition chemical models have recently been used in engine modelling stud- ies. Both single-zone and multi-zone chemical kinetics models have been developed [9-12]. With the multi-zone model, it was found that the temperature inhomogeneity and thermal boundary layers have an important influence on HCCI/CAI combustion. Amano et al. [9] found that the high-temperature region in the centre of the chamber is more likely to autoignite. Engdar et al. [10] and Fiveland and Assanis [11] reported that the boundary layer and crevice zones are not the reason for formation of HC in HCCI combustion. However, Easley et al. [12] found that the $\mathrm{CO}$ emissions were mainly formed from unburned fuel-air mixture flowing from the boundary layer and crevice zones into the higher temperature parts of the cylinder during the expansion stroke, where they were partially oxidized to form $\mathrm{CO}$. These results demonstrate that the effect of inhomogeneity on HCCI/ CAI combustion is important, because in-cylinder charge conditions are never completely homogeneous, especially for direct fuel injection engines. In parallel, visualizations of the $\mathrm{HCCI} / \mathrm{CAI}$ combustion process have been performed. Hultqvist et al. [13] used chemiluminescence imaging to observe the two-stage ignition process of HCCI combustion and found cool flames in the first-stage ignition and multiple-site combustion in the second-stage ignition. Zhao et al. [14] and Richter et al. [15] utilized the laser-induced fluorescence (LIF) method to investigate the fuel concentration distribution in the cylinder and its effect on HCCI/CAI combustion. Iwabuchi et al. [16] directly observed the effect of the mixture quality on $\mathrm{HCCI} / \mathrm{CAI}$ combustion in a direct injection diesel engine with early injection. However, fundamental understanding of the HCCI combustion process is still limited.

Currently, there are still challenges associated with the efficient application of this new combustion process to engines. One of the difficulties is that the $\mathrm{HCCI} / \mathrm{CAI}$ combustion operation is limited to a narrow part-load range. When the load is high (low air-fuel ratio or low EGR rate), the combustion can become unstable and knocking combustion can occur. In addition, the emission benefits also vanish at high-load conditions. Another problem of HCCI/CAI combustion is its relatively high unburned hydrocarbon ( $\mathrm{HC}$ ), especially when the mixture becomes very lean. A better understanding of the combustion process is necessary in order to apply it to production engines. The objective of the current work is directly to visualize the real $\mathrm{HCCI} / \mathrm{CAI}$ combustion autoignition process in the cylinder, using the planar laser-induced fluorescence (PLIF) method. No external tracer was added to the mixture. Formaldehyde formed during autoignition was used as the excited species. Investigations were carried out in an optical engine that has been especially adapted to meet the demands of two-dimensional PLIF measurements. The engine is also capable of strong charge stratification, so the effect of this can be studied. The intention of this work was to characterize the two-stage autoignition 
of $\mathrm{HCCI} / \mathrm{CAI}$ combustion with several fuel blends and directly to observe the effects of mixture quality and other engine operating conditions on $\mathrm{HCCI} / \mathrm{CAI}$ combustion.

\section{EXPERIMENTAL}

\subsection{Optical engine}

Investigations were carried out in an optical engine that has been specially adapted to meet the demands of twodimensional PLIF measurements, as shown in Fig. 1. The engine is based on the crankcase of a single-cylinder Lister-Petter diesel engine. Details of the engine are given in Table 1 . The engine retains the original crankcase and cylinder block, but a completely new cylinder head block was designed to provide the large optical access and to achieve mixture stratification in a controlled manner.

This engine has a disc-shaped combustion chamber. An optical window in the cylinder head permits a complete view of the combustion chamber. Two side windows are flush-mounted in the cylinder head block for

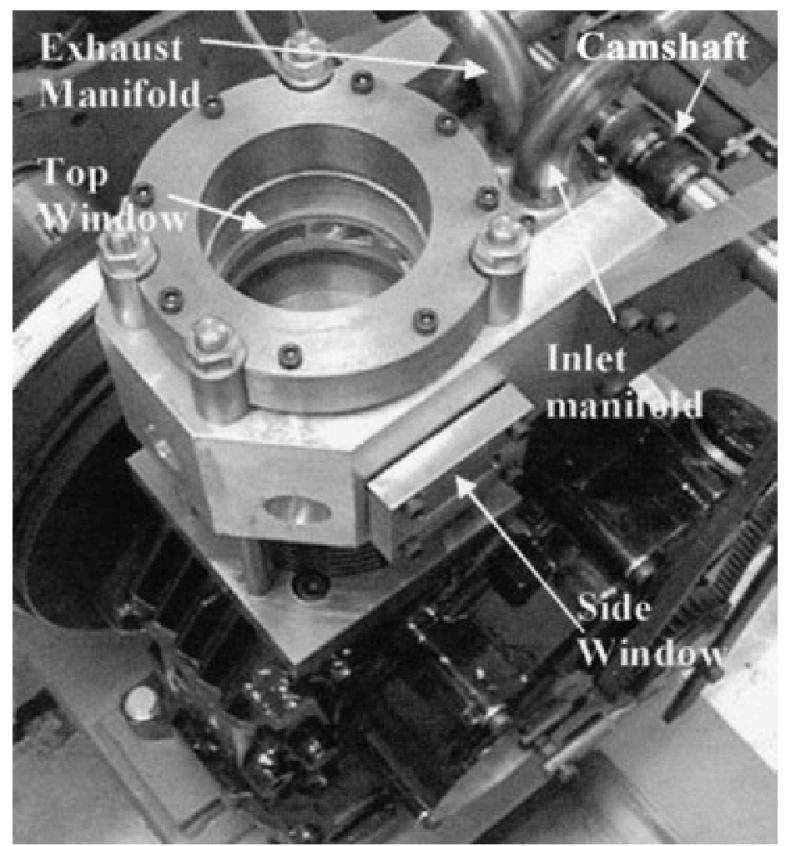

Fig. 1 Photograph of the optical engine

Table 1 Details of the single-cylinder optical engine

\begin{tabular}{ll}
\hline Bore & $95.3 \mathrm{~mm}$ \\
Stroke & $89 \mathrm{~mm}$ \\
Compression ratio & $10: 1$ \\
Intake valve opening & 30 CAD ATDC \\
Intake valve closure & 20 CAD ABDC \\
Exhaust valve opening & 20 CAD ABDC \\
Exhaust valve closure & 30 CAD BTDC \\
Valve diameter & $19 \mathrm{~mm}$ \\
Valve lift & $4 \mathrm{~mm}$ \\
\hline
\end{tabular}

transmission of a laser sheet. The intake and exhaust valves are located on another side of the cylinder head block. The two intake valves are positioned so that they are shrouded by the cylinder wall, resulting in two concentric flows in the combustion chamber during the intake valve opening period, as shown in Fig. 2. The burnt gases leave the combustion chamber through the third side valve.

The camshaft is mounted across the side of the engine and is belt-driven from the original cam in the crankcase. The cam lobes are threaded on to the shaft and are locked in place by threaded rings. This provides an easily adjustable way of altering valve phasing. The cam profile can be altered by mounting different cam lobes. The flexible design of the valve actuation system allows various combinations of combustible charge and diluents to be achieved by varying each valve's lift and phasing. For example, the quantity of residual gases trapped in the cylinder can be altered by controlling the exhaust valve duration and timing. This is necessary for the HCCI combustion study. The original piston was modified to accept a flat piston top, which is interchangeable. The compression ratio can be altered by means of various thickness spacer plates under the piston crown.

The engine is mounted on a test bed and coupled directly to a d.c. electric motor. The d.c. motor is controlled by a four-quadrant controller and is used to either motor or brake the engine as required. Fuel is injected into the inlet tract by a port fuel injection (PFI) injector, at a location $20 \mathrm{~cm}$ upstream of the intake valves. The fuelling system comprises a nitrogen pressurized steel cylinder, a fuel line, a PFI injector and an injector controller. A $3 \mathrm{~kW}$ air heater is installed further upstream

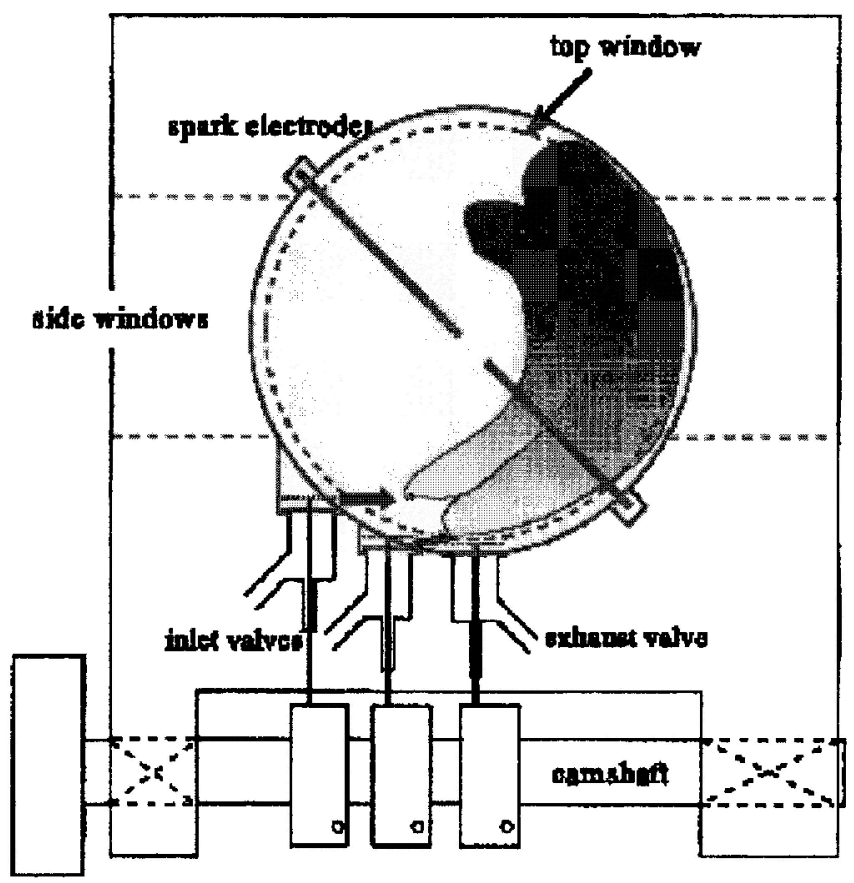

Fig. 2 Schematic of the cylinder head 
of the injector to provide intake air heating when it is needed.

Heat-release analysis is performed by a PC-based dataacquisition system. A real-time analysis program has been developed at Brunel University based on the Labview $^{\circledR}$ data-acquisition system. The system reads inputs from a crankshaft encoder and an in-cylinder pressure transducer (Kistler type 7061B) and the calculation of the heat-release rate is based on the heat-release formula suggested by Heywood [17]. The mass fraction burned is assumed to be the integration of the heatrelease rate.

\subsection{Formaldehyde two-dimensional PLIF measurement}

For in-cylinder measurements, LIF can be used to investigate fuel distributions, temperature distributions and combustion species. The principle of LIF and its application to internal combustion (IC) engines have been described by Zhao and Ladommatos [18]. For LIF, either fluorescence from a dopant molecule or from a reacting species can be used. In this study, an important intermediate of autoignition reactions, formaldehyde, is chosen as the source of fluorescence.

PLIF of formaldehyde has been used previously in combustion studies. Kosaka et al. [19] used two-dimensional formaldehyde LIF to investigate the ignition process of a conventional diesel fuel spray. Bäuerle et al. [20] observed hot spots of a gasoline engine using LIF of formaldehyde formed during knocking combustion. Schieß1 and Maas [21] found that there was a strong correlation between the temperature and the formaldehyde concentration in the unburned endgas of an SI engine. Then they detected temperature fluctuations by means of measuring spatial change in the formaldehyde concentration. In this study, based on the excitation spectrum of formaldehyde [22] and previous works $[19,20]$, the $4_{0}^{1}$ transition of $\tilde{A}^{1} A_{2} \leftarrow \tilde{X}^{1} A_{1}$ was used as the excitation line. A dye laser (Sira Cobra-Stretch dye laser), with pyridine as the dye and with a frequencydoubling device, was used to excite the formaldehyde. The dye laser was pumped by a Surelite I YAG (yttrium aluminium garnet) laser $(245 \mathrm{~mJ}$ output at $532 \mathrm{~nm})$. In order to verify and tune the dye laser output to the $4_{0}^{1}$ transition line, a premixed formaldehyde/air mixture was placed in a constant-volume vessel at 1 bar pressure and room temperature. After it was heated to $100^{\circ} \mathrm{C}$, LIF was measured. By scanning the excitation laser wavelength, it was found that the LIF signal was strongest at the $355 \mathrm{~nm}$ dye laser wavelength. At this wavelength, the dye laser had a pulse energy of $7 \mathrm{~mJ}$.

In the engine experiment, the output from the dye laser $(355 \mathrm{~nm})$ was steered via laser mirrors and then passed through a spherical lens $(f=1000 \mathrm{~mm})$ and two cylindrical lenses $(f=-40 \mathrm{~mm}, 75 \mathrm{~mm})$ to form a horizontal laser sheet, as shown in Fig. 3. The laser sheet passed through the entrance and exit windows on the side of the cylinder.

LIF and radiation from HCCI combustion were detected through the top window in the cylinder head. The signal was viewed via a $45^{\circ}$ mirror, mounted above the cylinder head and imaged on to a gated intensified charge-coupled device (ICCD) camera (LOT-Oriel Instraspec $\mathrm{V}, 385 \times 578$ pixels). The laser was triggered at a required crank angle in the engine cycle via a crank angle delay generator, with an input signal from a shaft encoder coupled to the camshaft. The intensifier delay and gate width were set via a signal delay generator (Stanford Research DG535) to coincide with lasing.

With careful adjustment to the delay and the gate settings of the ICCD, the interference of the laser signal on

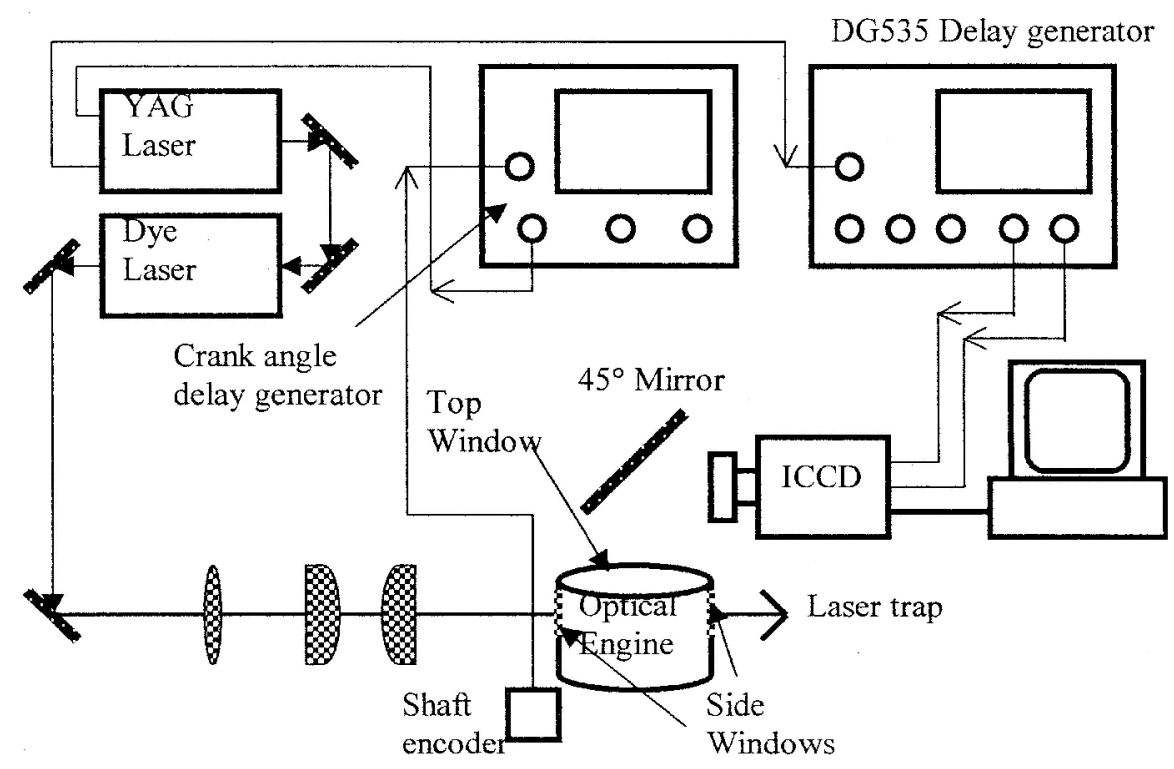

Fig. 3 Experimental set-up of the two-dimensional PLIF system 


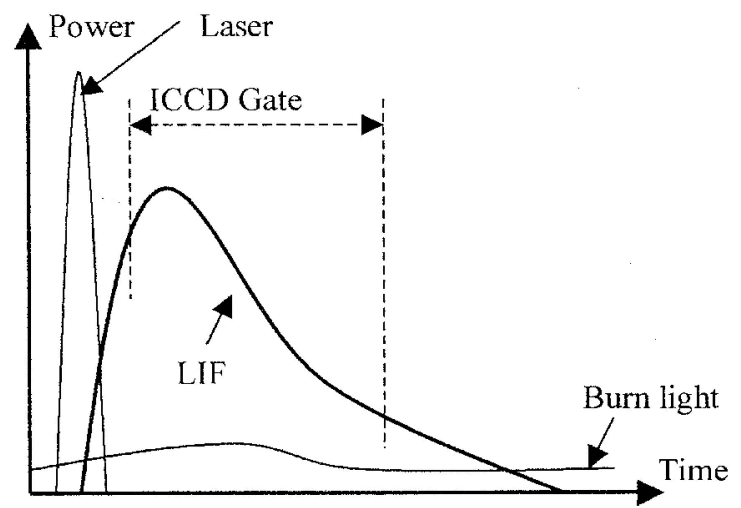

Fig. 4 Setting of the ICCD delay and its gate width

the LIF signal could be removed thoroughly without any optical filter. At first, the delay of the ICCD was increased gradually from the laser firing time until the effect of the laser pulse on the LIF signal disappeared. This was followed by setting the ICCD gate to a suitable value to obtain a good LIF image. The approach is shown schematically in Fig. 4. In the currently reported investigation, the gate width was set to $200 \mathrm{~ns}$ and the delay was $885 \mathrm{~ns}$, including the delay in the systems.

As the YAG laser can only run at a frequency of $10 \mathrm{~Hz}$, these experiments were carried out at an engine speed of $600 \mathrm{r} / \mathrm{min}$ to match the laser firing frequency. At this speed, HCCI/CAI combustion was achieved with a $100^{\circ} \mathrm{C}$ intake temperature for three fuel blends with different research octane numbers (RON). Those fuels were 100 per cent (by volume) n-heptane, 70 per cent n-heptane/30 per cent iso-octane and 40 per cent $\mathrm{n}$-heptane/60 per cent iso-octane respectively. Pure $\mathrm{n}$-heptane was tested as a 'basicline' fuel, as it has been shown to exhibit a typical two-stage heat release in HCCI/CAI combustion [23]. The engine was left to warm up for a few minutes before steady $\mathrm{HCCI} / \mathrm{CAI}$ combustion was achieved. Then the laser system and the image acquisition system were switched on for image acquisition. With the currently reported set-up, it was possible to take only one formaldehyde PLIF image per engine cycle.

\section{RESULTS AND DISCUSSION}

\subsection{Effect of charge conditions on autoignition}

The optical engine used in this study can produce a very strong charge stratification. This has been described in detail in reference [14]. Although the exhaust valve opening and closing timings have been readjusted compared with those adopted previously [14], in order to get more residual gas in the cylinder, in-cylinder fuel concentration and temperature distribution trends were similar to those measured in reference [14]. The residual gas proportion was highest in the central area of the cylinder. The closer to the cylinder wall, the lower was the residual gas proportion. Hence, the temperature was highest and the fuel concentration lowest in the central area; they gradually decreased and increased respectively, from the central area to the near-wall area. Other operating parameters (engine speed, intake temperature, fuel injection rate, etc.) were kept constant.

The air-fuel ratio and EGR rate were determined from the fuel flowrate and air flowrate. Firstly, the amount of fuel injected and the air flow into the cylinder were measured over a 5 min period under set engine operating conditions. Then the averaged fuel and air flowrates per cycle could be calculated and used to determine the air-fuel ratio. The residual gas concentration was estimated from the maximum cylinder volume minus the fresh air amount per cycle. The total measured residual gas proportion in the cylinder was 56 per cent by volume and the relative air-fuel ratio $\lambda$ was 2.2 .

Shown in Fig. 5 are two-dimensional PLIF images of formaldehyde for 100 per cent n-heptane from the time of the start of the low-temperature reaction to the end of the second stage of combustion. The values of crank angles at which those PLIF images were recorded are shown on the bottom-right corner of each frame. The number on the upper-left corner of each frame is the ICCD signal intensity parameter; a greater value implies a stronger LIF signal.

Those images show the variation of the formaldehyde concentration during $\mathrm{HCCI} / \mathrm{CAI}$ combustion. From the first frame, it can be seen that formaldehyde has appeared as early as 27 CAD BTDC, although its signal is very weak. In addition, on these images, it can be seen that the effect of the laser sheet divergence and attenuation on the LIF signal must be taken into account, in particular, for those images with a very weak LIF signal. The laser beam attenuation, where the laser intensity per unit area gradually becomes weaker from the entrance to the exit, is the cause of the LIF signal on the righthand side of the images being stronger than that on the left-hand side (e.g. in frame 2). The laser sheet divergence, which results in the laser intensity per unit area being strongest around the central line and gradually weaker towards the upper and bottom edges, leads to the case where the LIF signal is stronger around the central line, even with a near-homogeneous formaldehyde distribution (e.g. in frame 3). However, as the aim of this investigation is to provide more qualitative, not quantitative, information, the required information was not misunderstood significantly and those errors should be tolerated.

From the mass fraction burnt trace shown in Fig. 6, it can be seen that at 27 CAD BTDC a small amount of heat is being released. This suggests that the appearance of formaldehyde is approximately synchronized with the start of the low-temperature heat-release reactions for 100 per cent $n$-heptane. It should also be noted that formaldehyde mainly appears at the central area of 

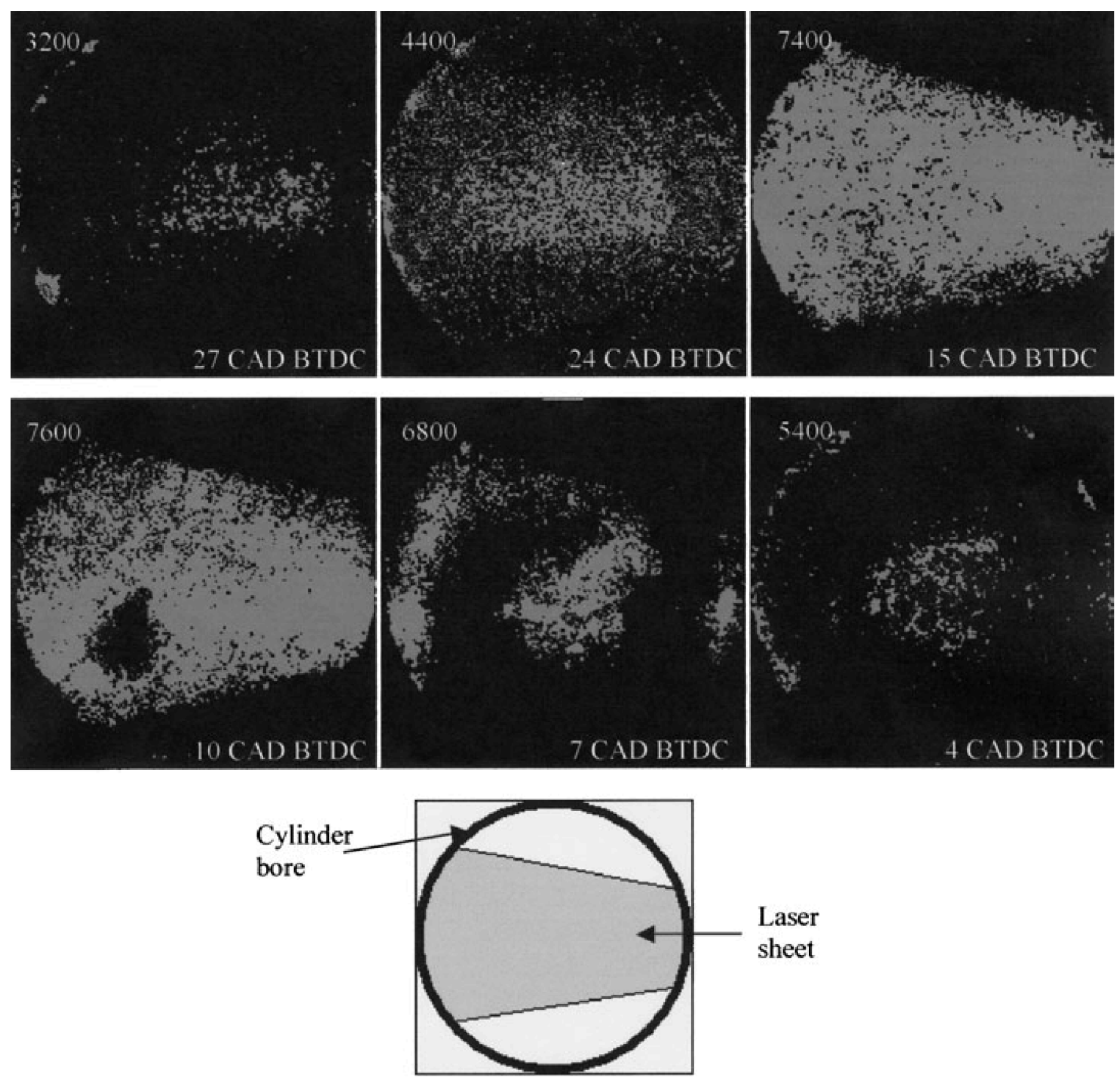

Fig. 5 Two-dimensional PLIF images of HCCI combustion of 100 per cent n-heptane

the cylinder. This suggests that the charge condition (temperature, fuel concentration, etc.) plays a very important role in the start of low-temperature reaction in the autoignition combustion process. As strong in-cylinder swirl, produced by the intake valves, pushes most of the hot residual gases into the central area, the charge temperature in the central area is probably higher than anywhere in the cylinder. As the fuel concentration is very low in this hot central area, it suggests that the charge temperature is much more important than the fuel concentration for initiating the low-temperature reaction.

With the progress of the engine compression stroke, charge temperatures in other areas gradually increase and reach the critical temperature for the low-temperature reaction. As a result, the area of formaldehyde expands from the central area to the near-wall area (see frame 2). At 15 CAD BTDC, the formaldehyde concentration is strongest and is almost homogeneous across the entire cylinder (frame 3). From Fig. 6, it can be seen that this corresponds to the end of the negative temperature coefficient (NTC) stage and just prior to the start of the main heat-release stage (the main combustion stage). From the fourth frame of the PLIF images, some 'holes' start to appear in the formaldehyde PLIF image. The mass fraction burnt graph in Fig. 6 suggests that this corresponds to the start of the second combustion stage.

However, the earliest hot autoignition does not occur in the central area, where the low-temperature reaction first started. It always starts in the middle area, between the central region and the area at the perimeter of the cylinder. As this middle region has neither the highest temperature nor the highest fuel concentration, it suggests that some appropriate combination temperature and fuel concentration is necessary for obtaining hightemperature ignition.

In order to further confirm the position and the time 


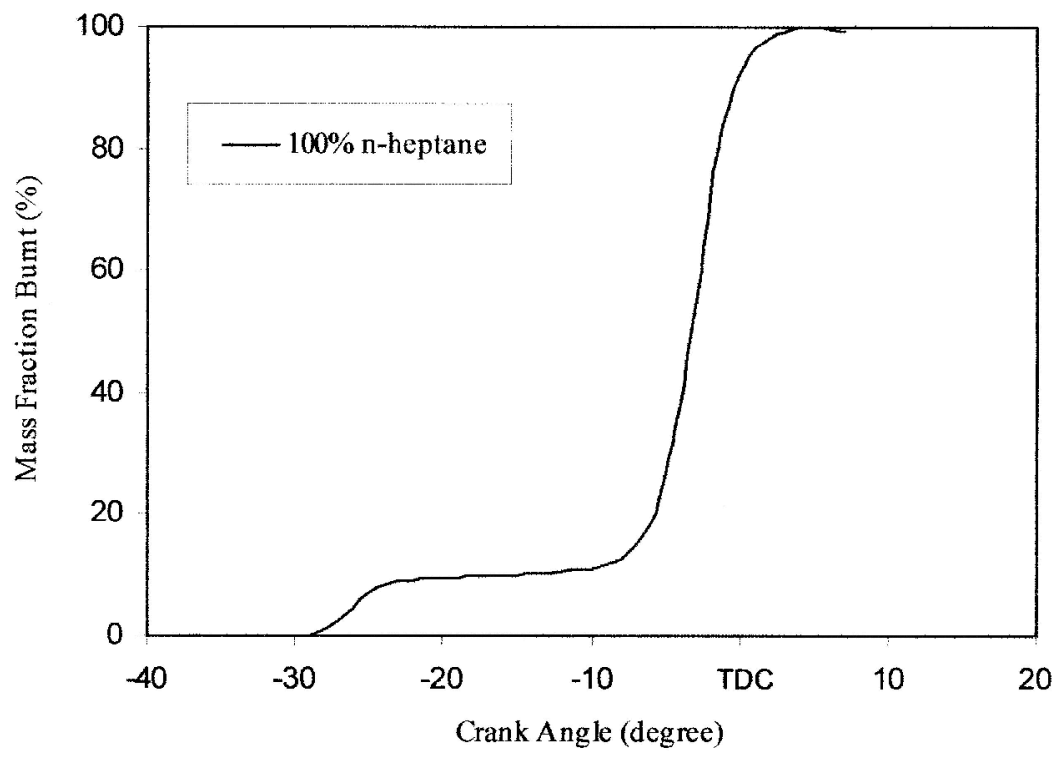

Fig. 6 Mass fraction burnt as a function of crank angle

of the hot ignition, some direct images of autoignition combustion were taken (Fig. 7). Those images were taken under the same combustion conditions as for the LIF images shown previously in Fig. 5, but with a much longer ICCD gating $(20 \mu \mathrm{s})$. By comparison with the previous LIF images, and noting that the lowtemperature reaction is difficult to see by direct imaging, the reacting regions shown on the direct combustion images are thought to correspond to the main heat-release stage of combustion. However, it is clear that the earliest hot combustion occurs neither in the central area (where the charge has the highest temperature) nor in the perimeter area (where the charge has the highest fuel concentration).

In the subsequent frames 2, 3 and 4 of Fig. 7 (direct images), it can be seen that the hot autoignition proceeds to the perimeter areas near the cylinder wall. These autoignition sites then expand towards the centre of the
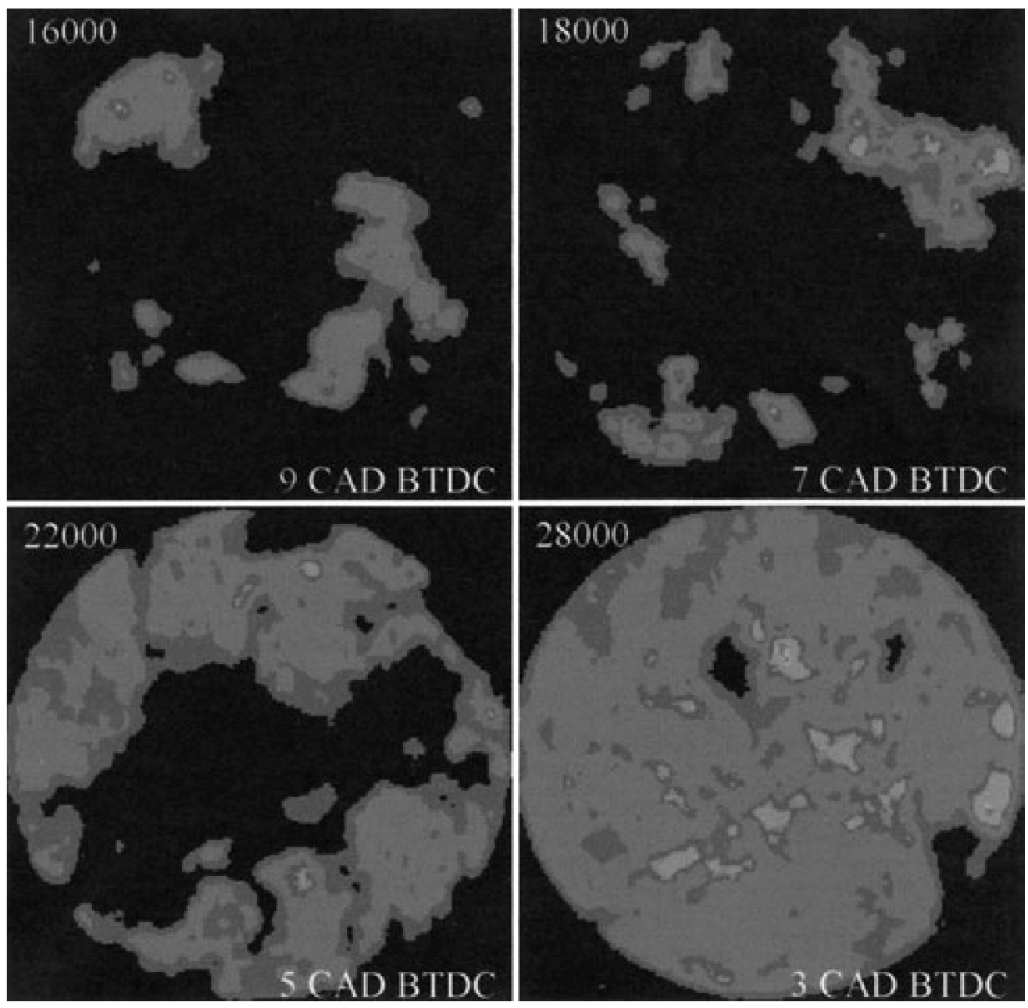

Fig. 7 Direct images of HCCI combustion for 100 per cent $n$-heptane 
combustion chamber, independently from the earliest combustion point seen in frame 1. This demonstrates that the initial temperature distribution has not dominated the development of the hot autoignition stage. One possible reason is that the second stage of n-heptane autoignition combustion probably depends more on the fuel concentration than on the charge temperature. Another possibility is that, after the low-temperature reaction, the in-cylinder temperature distribution may have been changed. Perimeter areas with a higher fuel concentration could have a higher temperature after the low-temperature reaction. This needs further investigation by measurement of the in-cylinder temperature distribution using LIF etc. laser techniques [24].

It is noted that, in frames 5 and 6 of Fig. 5 (PLIF images), the holes observed in the formaldehyde PLIF image expand to areas near the cylinder wall as well. The formaldehyde in the central area is burnt last. Combining those PLIF images with the direct images of hot autoignition, it is apparent that formaldehyde, produced during the low-temperature and the NTC stage, is consumed in the second stage of combustion.

Formaldehyde is formed first and burned last in the central area, where there is the highest residual gas concentration. That suggests that higher EGR concentration results in a longer combustion period for autoignited combustion, even though the higher charge temperature caused by this higher EGR concentration may result in earlier timing of the initial low-temperature reaction.

\subsection{Comparison for different fuels}

To investigate the effect of the fuel on the autoignited combustion process, three fuel blends were tested; $\mathrm{n}$-heptane and iso-octane were mixed in different proportions to simulate different RON fuels. Experiments with the different fuels were carried out under the same engine operating conditions and with the same intake temperature used previously. The fuelling was also kept constant, by using the same injection settings. Shown in Fig. 8 are the earliest formaldehyde appearance images for the three different fuel blends. Crank angles at which the three images were taken are 27 CAD BTDC for 100 per cent n-heptane, $26 \mathrm{CAD}$ BTDC for 70 per cent n-heptane/30 per cent iso-octane and 25 CAD BTDC for 40 per cent $n$-heptane/60 per cent iso-octane respectively. The images shown in Fig. 8 suggest that the timing of the start of the low-temperature reaction is very similar for all three fuels, although the observed PLIF intensity falls with a reduced n-heptane content.

However, the mass fraction burnt curves (Fig. 9) show no low-temperature heat release for the two non-100 per cent n-heptane fuels. Nevertheless, low-temperature reactions do occur with those fuels and a certain amount of formaldehyde is formed (Fig. 8), if there is a reduced $\mathrm{n}$-heptane content. These results indicate that the presence of iso-octane has little effect on the timing of the start of the low-temperature reaction, even though it significantly reduced the amount of heat released during the low-temperature reaction period.

The timing of the various stages in the autoignition event for the three fuel blends are also indicated in Fig. 9 from the start of formaldehyde formation through its peak and subsequent disappearance. Those timings are derived from PLIF signals. The timings of the first formaldehyde appearance and strongest LIF signals for the three fuels are similar. However, the start of the main heat-release combustion stage is very different. This corresponds to the difference shown in the mass fraction burnt curves.

Shown in Fig. 10, for the three fuels, are images at the instant where the formaldehyde just begins to burn. Although those times are very different for the three fuels, the locations where formaldehyde begins to be burnt are similar for all three fuels, mostly in the middle region (between the central and the perimeter areas). The different timings (10 CAD BTDC for 100 per cent n-heptane, 2 CAD BTDC for 70 per cent n-heptane/30 per cent iso-octane and 2 CAD ATDC for 40 per cent

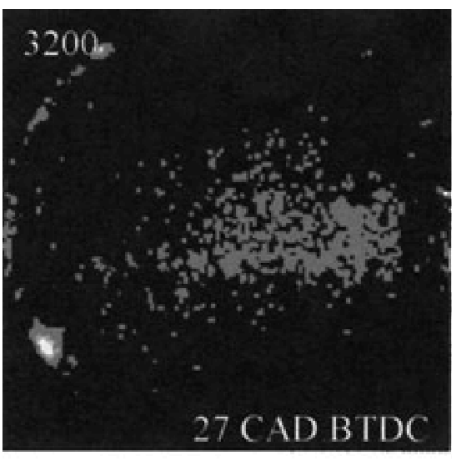

(a) $100 \%$ n-heptane

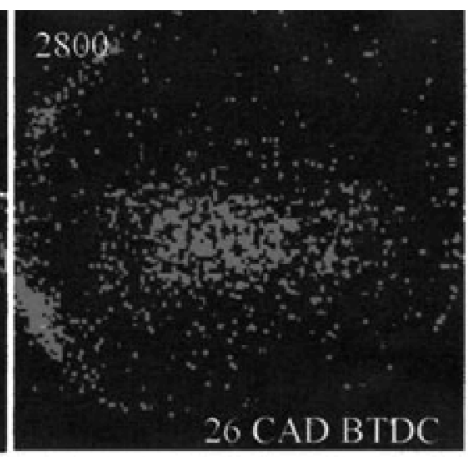

(b) $70 \%$ n-heptane/ $30 \%$ iso-octane

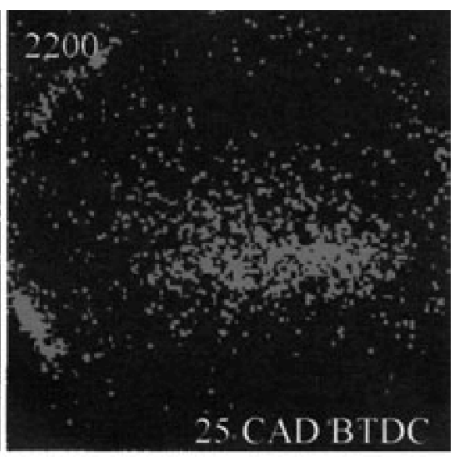

(c) $40 \%$ n-heptane/ $60 \%$ iso-octane

Fig. 8 Comparison of the beginning of the low-temperature reaction for the three different fuels 


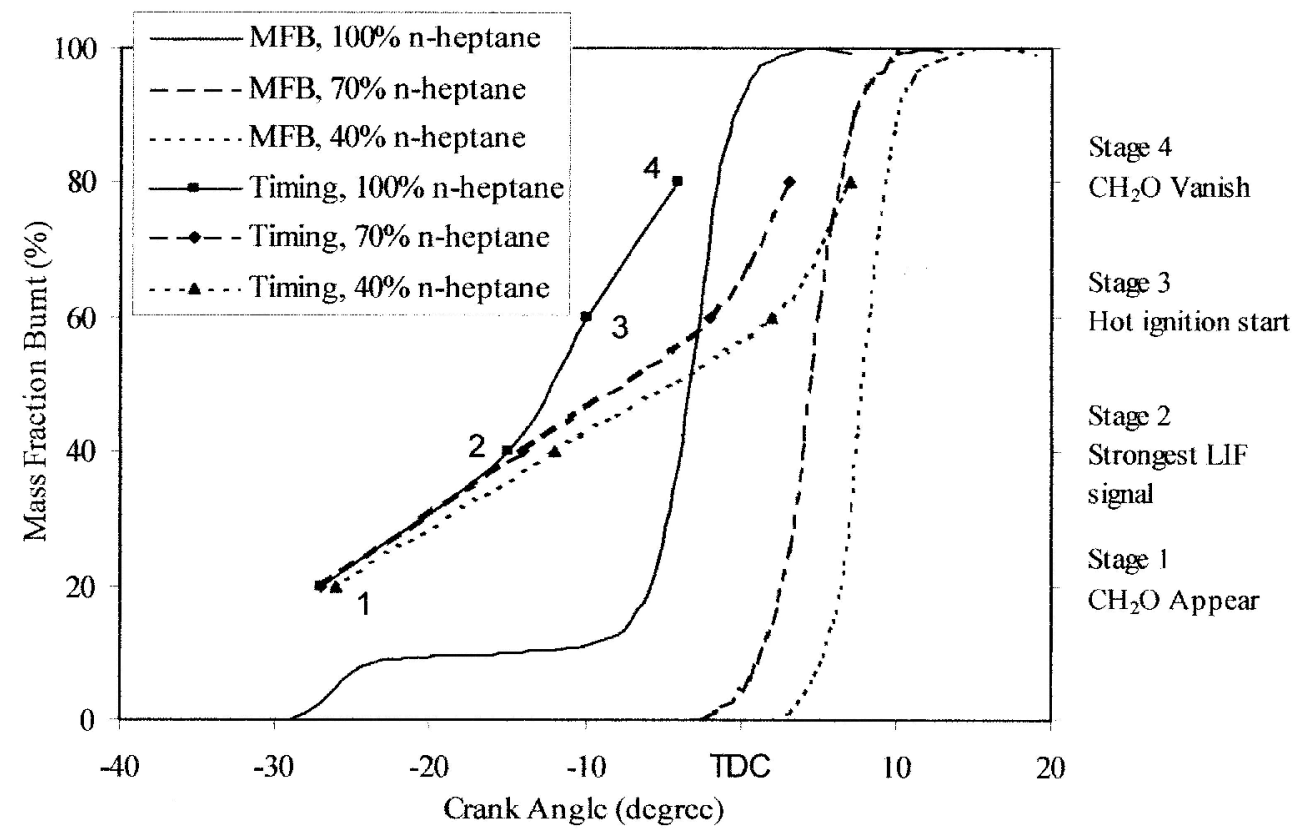

Fig. 9 Effect of different fuels on the mass fraction burnt (MFB) and autoignition timings

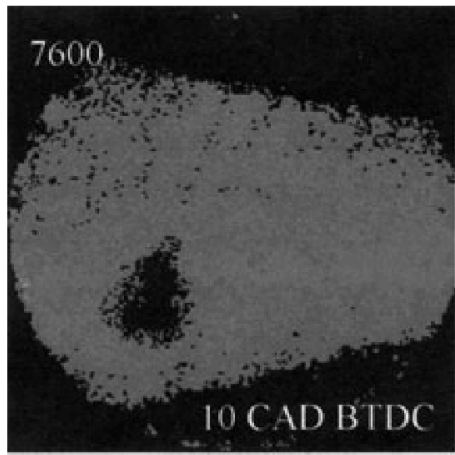

(a) $100 \%$ n-heptane

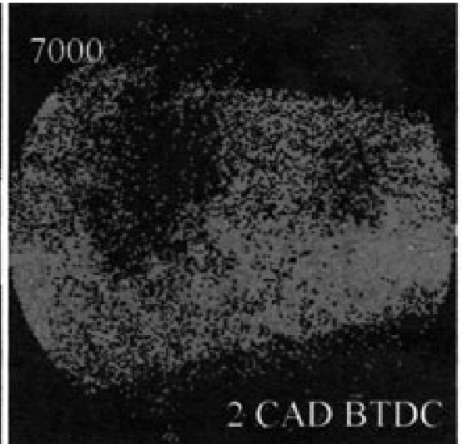

(b) $70 \%$ n-heptane/' $30 \%$ iso-octane

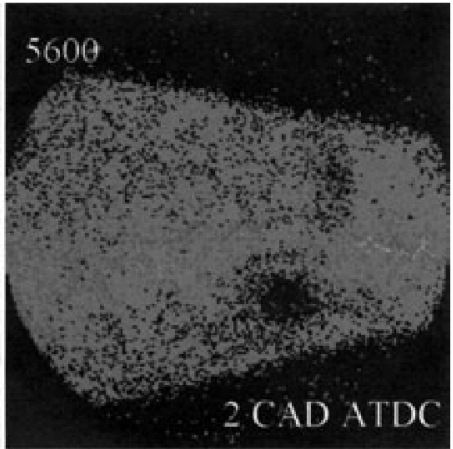

(c) $40 \%$ n-heptane/ $60 \%$ iso-octane

Fig. 10 Comparison of the start of hot ignition for the three different fuels

$\mathrm{n}$-heptane/60 per cent iso-octane respectively) suggest that a major effect of the presence of iso-octane in the fuels is to retard the start of the main heat-release combustion stage.

\section{SUMMARY}

An experimental investigation of the $\mathrm{HCCI} / \mathrm{CAI}$ combustion process has been carried out using twodimension PLIF of formaldehyde formed during the low-temperature reaction stage. PLIF of formaldehyde was detected by exciting formaldehyde at $355 \mathrm{~nm}$ wavelength using a tunable dye laser. Measurements were made for an optical engine capable of producing charge stratification. Timings and locations of the two-stage autoignition of three fuel blends of n-heptane and iso- octane were investigated. The main findings are summarized as follows:

1. Two-dimensional PLIF imaging of formaldehyde formed during HCCI combustion was successfully achieved.

2. For 100 per cent n-heptane, the appearance and subsequent burning of formaldehyde were found to coincide with the start of the low-temperature heat release and the main heat release respectively.

3. The start of the low-temperature reaction and formation of formaldehyde is mainly a function of the charge temperature. The start of the main combustion stage is affected by both the fuel concentration and the charge temperature.

4. The presence of iso-octane does not affect significantly the start of low-temperature reactions, suggest- 
ing that the onset is associated purely with n-heptane. However, it significantly reduces the amount of heat released during the low-temperature reaction period and retards the start of the main combustion process.

\section{REFERENCES}

1 Thring, R. H. Homogeneous charge compression ignition (HCCI) engines. SAE paper 892068, 1989.

2 Zhao, H., Peng, Z. and Ladommatos, N. Understanding of controlled autoignition combustion in a four-stroke gasoline engine. Proc. Instn Mech. Engrs, Part D: J. Automobile Engineering, 2001, 215(D12), 1297-1310.

3 Epping, K., Aceves, S., Bechtold, R. and Dec, J. The potential of HCCI combustion for high efficiency and low emissions. SAE paper 2002-01-1923, 2002.

4 Law, D., Kemp, D., Allen, J., Kirkpatrick, G. and Copland, T. Controlled combustion in an IC-engine with a fully variable valve train. SAE paper 2000-01-0251, 2000.

5 Wolters, P., Salber, W., Geiger, J. and Duesmann, M. Controlled auto ignition combustion process with an electromechanical valve train. SAE paper 2003-01-0032, 2003.

6 Cox, R. A. and Cole, J. A. Chemical aspects of the autoignition of hydrocarbon-air mixtures. Combust. Flame, 1985, 60, 109-123.

7 Curran, H. J., Gaffuri, P., Pitz, W. J. and Bestbrook, C. K. A comprehensive modeling study of n-heptane oxidation, Combust. Flame, 1998, 114, 149-177.

8 Tanaka, S., Ayala, F., Keck, J. C. and Heywood, J. B. Twostage ignition in HCCI combustion and HCCI control by fuels and additives. Combust. Flame, 2003, 132, 219-239.

9 Amano, T., Morimoto, S. and Kawabata, Y. Modeling of the effect of air/fuel ratio and temperature distribution on HCCI engines. SAE paper 2001-01-1024, 2001.

10 Engdar, U., Johansson, B. and Klingmann, J. Reacting boundary layers in a homogeneous charge compression ignition (HCCI) engine. SAE paper 2001-01-1032, 2001.

11 Fiveland, S. B. and Assanis, D. N. Development of a twozone HCCI combustion model accounting for boundary layer effects. SAE paper 2001-01-1028, 2001.

12 Easley, W. L., Agarwal, A. and Lavoie, G. A. Modeling of
HCCI combustion and emissions using detailed chemistry. SAE paper 2001-01-1029, 2001.

13 Hultqvist, A., Christensen, M., Johansson, B., Franke, A., Richter, M. and Alden, M. A study of the homogeneous charge compression ignition combustion process by chemiluminescence imaging. SAE paper 1999-01-3680, 1999.

14 Zhao, H., Peng, Z., Williams, J. and Ladommatos, N. Understanding the effects of recycled burnt gases on the controlled autoignition (CAI) combustion in four-stroke gasoline engines. SAE paper 2001-01-3607, 2001.

15 Richter, M., Franke. A., Alden, M., Hultqvist, A. and Johansson, B. Optical diagnostics applied to a naturally aspirated homogeneous charge compression ignition engine. SAE paper 1999-01-3649, 1999.

16 Iwabuchi, Y., Kawai, K., Shoji, T. and Takeda, Y. Trial of new concept diesel combustion system-premixed compression-ignition combustion. SAE paper 1999-01$0185,1999$.

17 Heywood, J. B. Internal Combustion Engine Fundamentals, 1988.

18 Zhao, H. and Ladommatos, N. Engine Combustion Instrumentation and Diagnostics, 2001 (SAE International, Warrendale, Pennsylvania).

19 Kosaka, H., Drewes, V. H., Catalfamo, L., Aradi, A. A., Lida, N. and Kamimoto, T. Two-dimensional imaging of formaldehyde formed during the ignition process of a diesel fuel spray. SAE paper 2000-01-0236, 2000.

20 Bäuerle, B., Hoffmann, F., Behrendt, F. and Warnatz, J. Detection of hot spots in the end gas of an internal combustion engine using two-dimensional LIF of formaldehyde, In Twenty-Fifth International Symposium on Combustion, 1994, pp. 135-141 (The Combustion Institute, Pittsburgh, Pennsylvania).

21 Schießl, R. and Maas, U. Analysis of temperature fluctuations in an SI engine by laser-induced fluorescence. Combust. Flame, 2003, 133, 19-27.

22 Miller, R. G. and Lee, E. K. C. Single vibronic level photochemistry of formaldehyde $\left(\mathrm{H}_{2} \mathrm{CO},{ }^{1} \mathrm{~A}_{2}\right)$ : radiative and non-radiative transitions. Chem. Physics Lett., 1975, 33(1), 104-107.

23 Peng, Z., Zhao, H. and Ladommatos, N. Effects of air/fuel ratios and EGR rates on HCCI combustion of $n$-heptane, a diesel type fuel. SAE Paper 2003-01-0747, 2003.

24 Einecke, S., Schulz, C., Sick, V., Schießl, R., Dreizler, A. and Maas, U. Two-dimensional temperature measurements in the compression stroke of an SI engine using two-line tracer LIF. SAE paper 982468, 1998. 